\title{
Statistical Analysis of Wind Speed for the Probability Evaluation of Cancelled Departure for Catamarans and Ferries
}

\author{
Nastia Degiuli \\ Faculty of Mechanical Engineering and Naval Architecture, University of \\ Zagreb, Croatia \\ Biserka Runje \\ Faculty of Mechanical Engineering and Naval Architecture, University of \\ Zagreb, Croatia \\ Andrea Farkas
}

Faculty of Mechanical Engineering and Naval Architecture, University of Zagreb, Croatia

\begin{abstract}
Weather data bases are important in optimizing a range of economic activities, such as maritime traffic. In this paper, a statistical analysis of data has been carried out, which includes the interpretation of the results with an emphasis on the analysis of consequences for local population. The proposed procedure is supported by realistic data for wind speed and direction measured at meteorological station Split in the period from 2002 to 2011 . Using available data, the annual as well as seasonal wind roses for the specified location are shown. Furthermore, wind speed data are approximated by the Weibull's probability distribution that enables estimating the probability of exceeding a particular wind speed, i.e. Beaufort number for this location. Thus, the probability of cancelled departure for catamarans, as well as ferries from the Split city port is determined for the annual level as well as for each season. The obtained results provide a more detailed insight into the important occurrence of cancelled departure of catamarans and ferries, significant for the lives of the islanders gravitating to Split.
\end{abstract}

Keywords: knowledge, information quality, applied statistics, probability estimation, wind, weibull distribution

JEL classification: C 15

\section{Introduction}

Weather data bases represent a large data bases collected in long period time. Sensors located on the land, oceans, in the atmosphere and space measure several parameters which determine weather. Data gathered by these sensors are essential for understanding weather and climate (U.S. Congress, Office of Technology Assessment, 1993.). Therefore, weather data bases have a wide range of applications, including optimization of range economic activities. Increase in the importance of wind power for electricity generation has led to significant growth of research in this area (Pishgar-Komleh et al., 2014). Lately, wind data bases are extremely important for the determination and analysis of wind energy (Seguro et al., 2000). For those analyses, average states of wind speed and direction in long period of time are used for the determination of average wind power. Beside general 
characteristics of weather, i.e. average states in long period of time, rare events and extreme meteorological conditions are even more significant for safety measures when designing different maritime or civil engineering structures. What is more, these events can be used for optimizing maritime traffic.

Wind power can be estimated visually according to wind effects on the objects in the nature and it is expressed in degrees of the Beaufort wind scale. This scale relates the wind speed with Beaufort force number (Meaden, G., 2007). The Beaufort wind scale is shown in table 1.

Table 1

Beaufort wind scale

\begin{tabular}{ccccc}
\hline $\begin{array}{c}\text { Beaufort } \\
\text { wind scale }\end{array}$ & Characteristics & $\begin{array}{c}\text { Wind speed, } \\
\mathrm{m} / \mathrm{s}\end{array}$ & \multicolumn{2}{c}{$\begin{array}{c}\text { Wave height, m } \\
\text { Maximum }\end{array}$} \\
\hline $\mathbf{0}$ & Calm & $0-0.2$ & - & \\
$\mathbf{1}$ & Light Air & $0.3-1.5$ & 0.1 & 0.1 \\
$\mathbf{2}$ & Light Breeze & $1.6-3.3$ & 0.2 & 0.3 \\
$\mathbf{3}$ & Gentle Breeze & $3.4-5.4$ & 0.6 & 1 \\
$\mathbf{4}$ & Moderate Breeze & $5.5-7.9$ & 1 & 1.5 \\
$\mathbf{5}$ & Fresh Breeze & $8-10.7$ & 2 & 2.5 \\
$\mathbf{6}$ & Strong Breeze & $10.8-13.8$ & 3 & 4 \\
$\mathbf{7}$ & Near Gale & $13.9-17.1$ & 4 & 5.5 \\
$\mathbf{8}$ & Gale & $17.2-20.7$ & 5.5 & 7.5 \\
$\mathbf{9}$ & Strong Gale & $20.8-24.4$ & 7 & 10 \\
\hline $\mathbf{1 0}$ & Storm & $24.5-28.4$ & 9 & 12.5 \\
\hline $\mathbf{1 1}$ & Violent Storm & $28.5-32.6$ & 11.5 & 16 \\
\hline Source: Pomorska enciklopedija (1989) & $\geq 32.7$ & $14-$ & - \\
\hline
\end{tabular}

In the literature, various probability density functions (PDF) are used to model the wind speed distributions. Omid et al. (2016) used exponential distribution, Sarkar et al. (2011) Extreme value distribution, Morgan et al. (2011) Gamma distribution, PishgarKomleh et al. (2015) Rayleigh distribution and Masseran et al. (2013) Inverse Gamma distribution. However, most of the authors use the Weibull PDF for modelling the wind speed distributions (Carillo et al. 2014, Christopher et al. 2017).

In this paper, the Weibull PDF is used for adjusting the wind speed data. The wind data was collected by measurements at the meteorological station Split in the period from 2002 to 2011 (ECA, 2015). Measured wind data (speed and direction) at the meteorological station are collected in a relatively rare network of measurement points at a height of $10 \mathrm{~m}$ above the ground to reduce the friction effect due to the roughness of the substrate. The wind speed and direction data for the Split area are obtained with the classical Fuess measurement system and the microM digital measuring system. However, in order to complete the picture of the wind regimes, data collected at the meteorological stations is used.

The most part of the year over the Adriatic dominate the winds of southern and northern directions (jugo and bura). South-eastern and southern winds bear common name jugo and prevail in the colder period of the year. Jugo is mostly blowing on the front of the Mediterranean or Adriatic cyclone and is among the most common wind directions on the Adriatic, both on the open sea and on the coast. The wind of northern and northeast directions on the eastern Adriatic coast is blowing throughout the year. It is a strong, gusty, colder and mostly dry wind known 
as bura. It is especially strong and dangerous in the cooler part of the year when it reaches speeds up to $50 \mathrm{~km} / \mathrm{h}$.

In this paper, in order to illustrate the wind regimes in the Split area, the annual and seasonal frequencies, i.e. probabilities of the occurrence of certain wind speed are analysed in order to determine the probability of exceeding a particular wind speed. Also, wind roses are obtained to further investigate the wind regimes.

\section{Methodology}

In order to model the wind speed distribution in the Split area, two parameter Weibull PDF is used. The Weibull distribution of wind speed is characterized by two functions: the probability density function (PDF) and the distribution function, i.e. cumulative distribution function. PDF of the Weibull distribution is presented as follows:

$$
f(v)= \begin{cases}\left(\frac{k}{v}\right)\left(\frac{v}{c}\right)^{k-1} \cdot e^{-\left(\frac{v}{c}\right)^{k}} & , v \geq 0 \\ 0 & , v<0\end{cases}
$$

(1)

where $c$ is the scale parameter, $k$ is the shape parameter and $v$ is the wind speed.

The distribution function can be obtained with following equation:

$$
F(v)=\int_{0}^{v} f(v) \mathrm{d} v
$$

Utilizing PDF, it is possible to estimate the probability of exceeding a particular wind speed $\tilde{v}$, i.e. the Beaufort number as follows:

$$
p(v \geq \tilde{v})=\int_{\tilde{v}}^{\infty} f(v) \mathrm{d} v=e^{-\left(\frac{\tilde{v}}{c}\right)^{k}}
$$

The Anderson-Darling test is used to test if a sample of data came from a population with a specific distribution. This test uses the specific distribution for calculation of critical values. The advantage of this approach is that it allows a more sensitive test and the disadvantage is that critical values must be calculated for each distribution. The Anderson-Darling test statistic is defined as (NIST/SEMATECH, 2013):

$A^{2}=-N-S$

where $S$ is defined as follows:

$S=\sum_{i=1}^{N} \frac{(2 i-1)}{N}\left[\ln F\left(Y_{i}\right)+\ln \left(1-F\left(Y_{N+1-i}\right)\right)\right]$

where $Y_{i}$ are the ordered data.

The sea state is the general condition of the free surface on a large body of water with respect to wind waves and swells at a particular location and time. The sea state can be assessed by an experienced observer, through weather buoys, wave radar or remote sensing satellites. The World Meteorological Organization (WMO) sea state code adopts the "wind sea" definition of the Douglas Sea Scale, shown in Table 2. The sea state is related to the Beaufort wind scale. 


\section{Table 2}

Sea state

\begin{tabular}{ccc}
\hline Sea state & Characteristics & Wave height, $\mathbf{m}$ \\
\hline 0 & Calm (glassy) & 0 \\
1 & Calm (rippled) & $0-0.1$ \\
2 & Smooth (wavelets) & $0.1-0.5$ \\
3 & Slight & $0.5-1.25$ \\
4 & Moderate & $1.25-2.5$ \\
5 & Rough & $2.5-4$ \\
6 & Very rough & $4-6$ \\
7 & High & $6-9$ \\
8 & Very high & $9-14$ \\
\hline 9 & Phenomenal & $>14$ \\
\hline
\end{tabular}

If a certain sea state is exceeded, captains usually make a decision not to depart from the port. Catamarans and ferries will not depart from the Split city port if the sea state is equal to or higher than 4. This value corresponds to 5 degrees of the Beaufort wind scale. Within this study, the probability of exceeding the medium wind speed of 5 degrees of the Beaufort wind scale is determined.

\section{Results and discussion}

A wind rose is a graphical tool used to give a succinct view of how wind speed and direction are typically distributed at a particular location. The wind rose is given in polar coordinate system. Typically, the wind rose shows the frequency or average speed of winds blowing from particular directions over a specified period. Wind roses are obtained for the annual level and for each season, Figure 1-Figure 5.

Figure 1

The annual wind rose regarding frequency (left) and average wind speed (right)
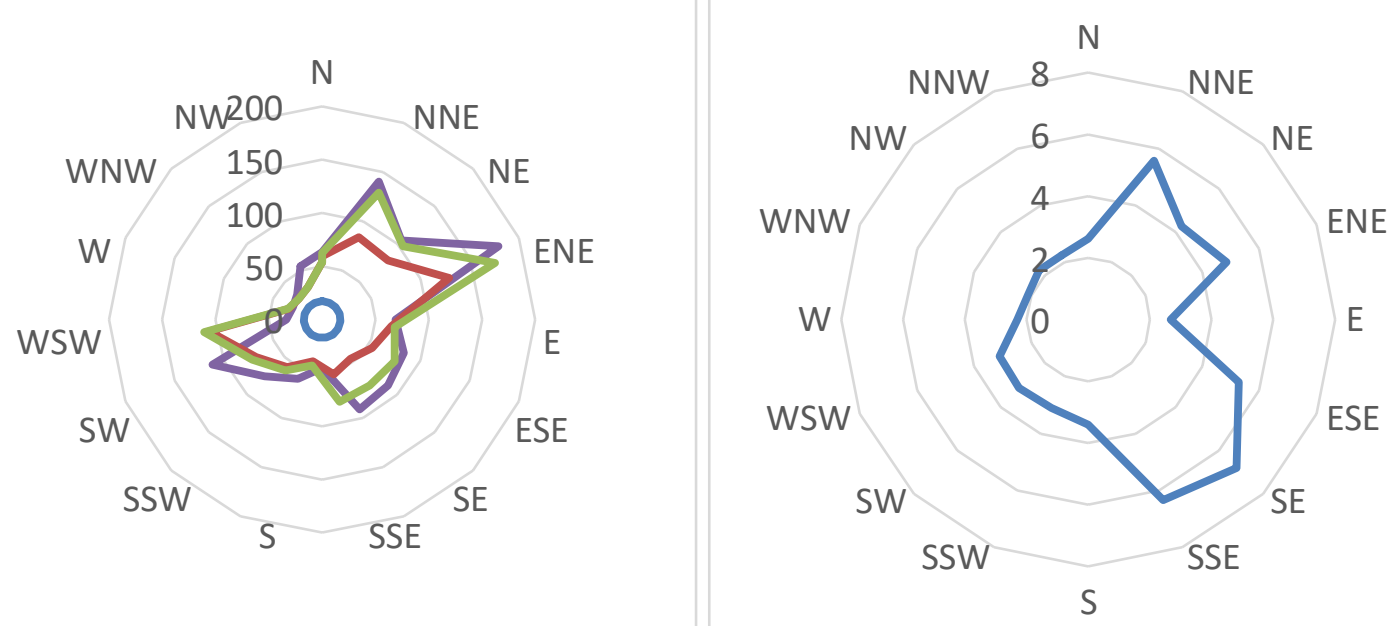

Source: Author's illustration 
Figure 2

Winter wind rose regarding frequency (left) and average wind speed (right)
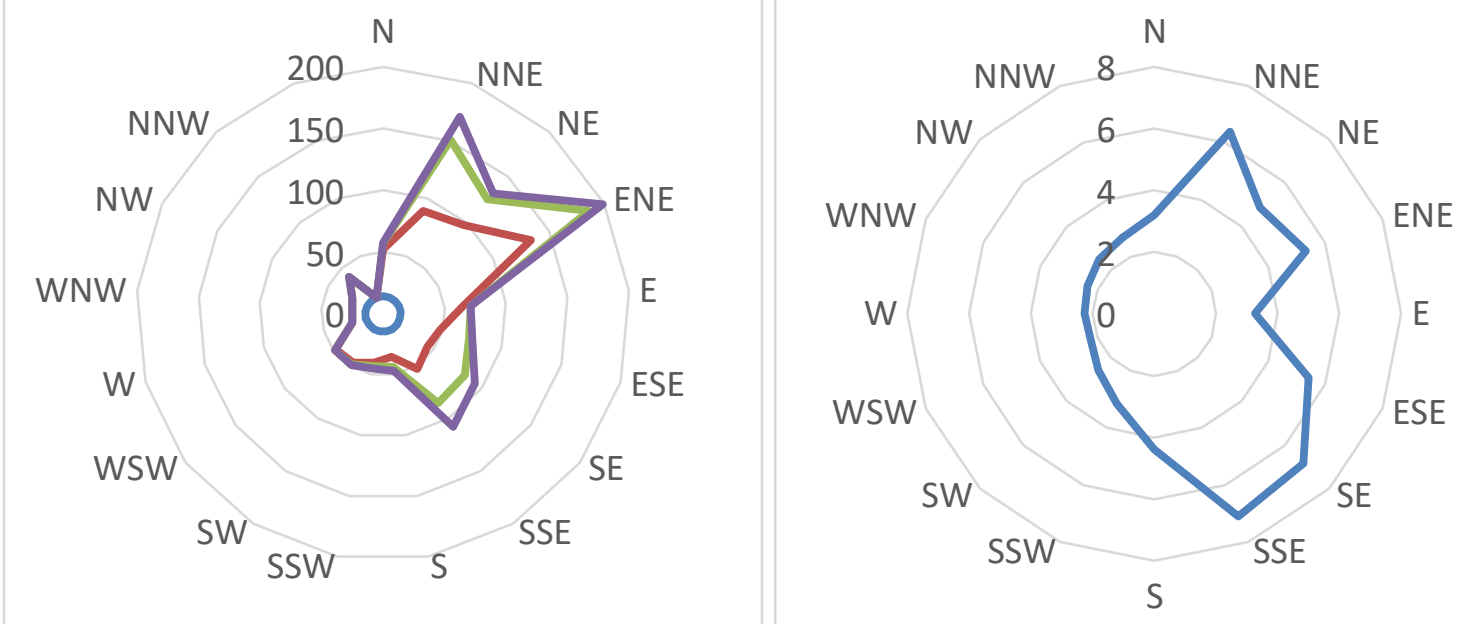

Source: Author's illustration

Figure 3

Spring wind rose regarding frequency (left) and average wind speed (right)
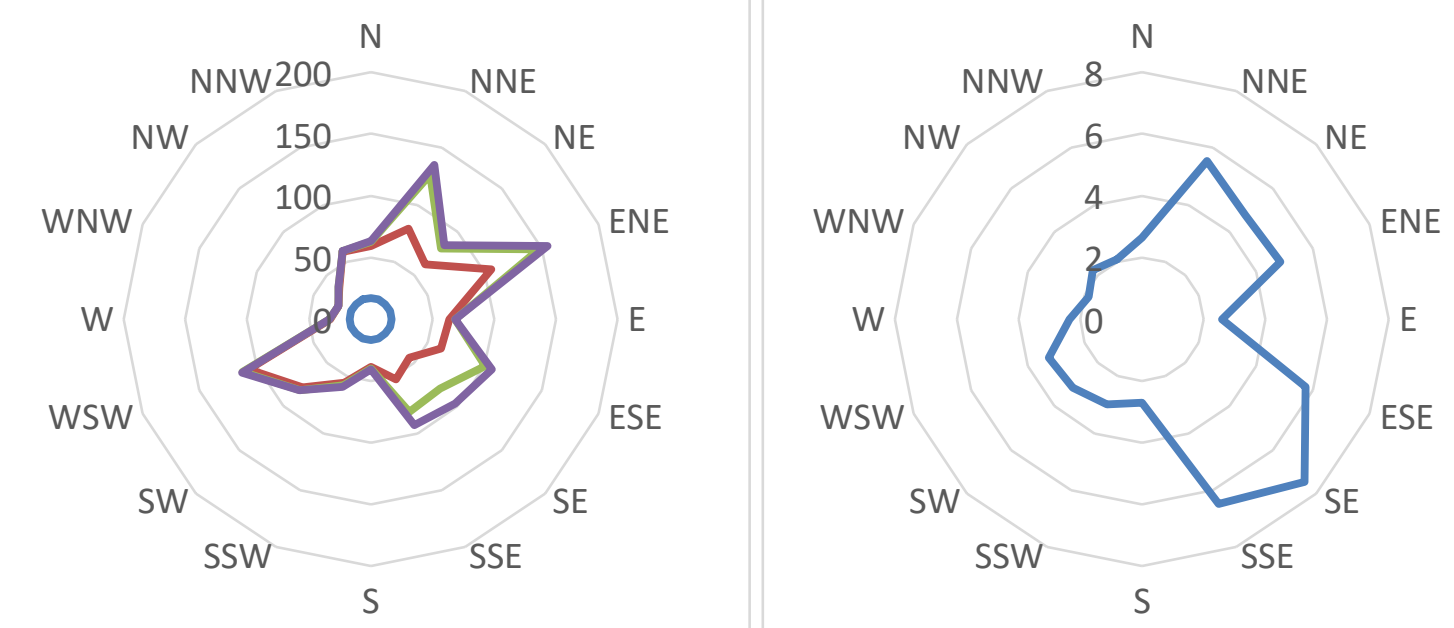

Source: Author's illustration 
Figure 4

Summer wind rose regarding frequency (left) and average wind speed (right)
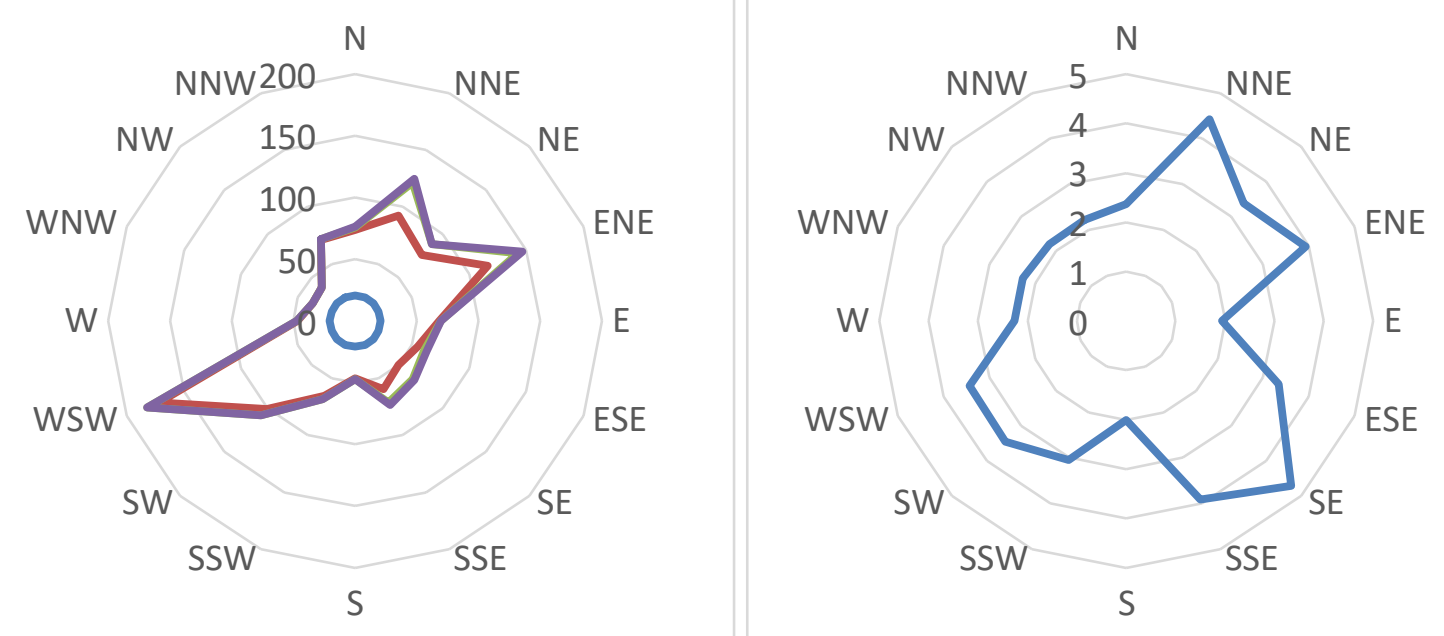

Source: Author's illustration

Figure 5

Autumn wind rose regarding frequency (left) and average wind speed (right)
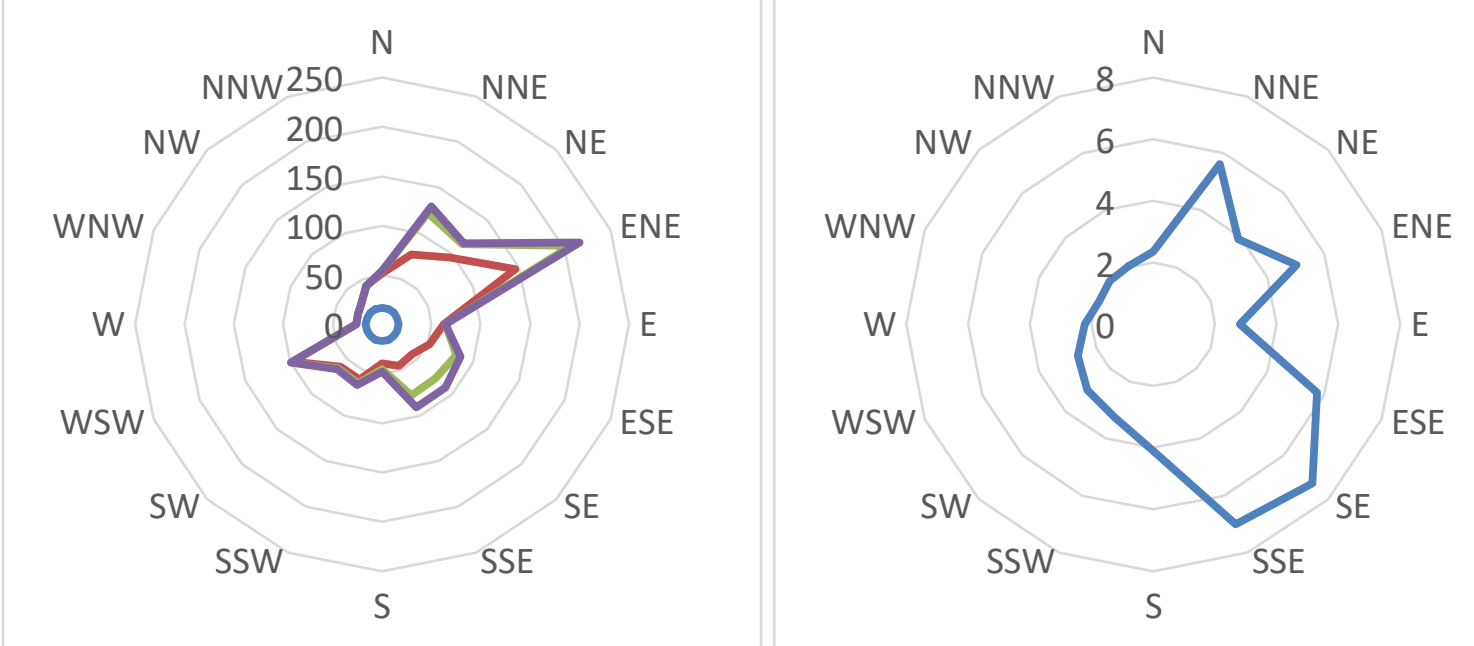

Source: Author's illustration

In the period from 2002 to 2011 , the most frequent wind directions in the Split area are: ENE (16.2\%), NNE (12.3\%), WSW (9.4\%) and SSE (7.4\%) cases of total number of data over the year. The highest average wind speeds in the Split area are present for: SE $(6.8 \mathrm{~m} / \mathrm{s})$, SEE $(6.34 \mathrm{~m} / \mathrm{s})$, NNE $(5.57 \mathrm{~m} / \mathrm{s})$ and ESE $(5.28 \mathrm{~m} / \mathrm{s})$.

The winds of ENE and NNE are the most common in this area. In every season they are most prominent, so their frequency ranges from $20.0 \%$ in the autumn to $12.6 \%$ in the summer. In the winter, the SSE wind appears with the frequency of about $9.3 \%$, while in the summer it has frequency equal to 5.3\%. WNW wind (maestral) is more pronounced in the summer (16.2\%) than in the other parts of the year, which is understandable, as maestral appears in the warmer part of the year. Its frequency is the smallest in the autumn $(0.1 \%)$. Calm wind condition in the split area is most frequent in the summer $(2.1 \%)$. In the spring and autumn, the frequency of calm wind condition is equal to $1.7 \%$, while the lowest frequency is in the winter (1.4\%). At the annual level, the percentage of calm wind condition is about $1.7 \%$. The winds of SE 
have the highest average wind speed in all seasons. The average speed of SE winds is in the spring is equal to $7.46 \mathrm{~m} / \mathrm{s}$, in the autumn $7.29 \mathrm{~m} / \mathrm{s}$, in the winter $6.85 \mathrm{~m} / \mathrm{s}$ and in the summer $4.73 \mathrm{~m} / \mathrm{s}$. It is important to notice that this statistic refers to the average of wind speeds and directions taken at one hour time interval, not to the current wind speeds and directions. Therefore, bura wind has somewhat smaller average wind speeds, since these winds are gusty winds.

Figure 6

Anderson-Darling test for the annual level

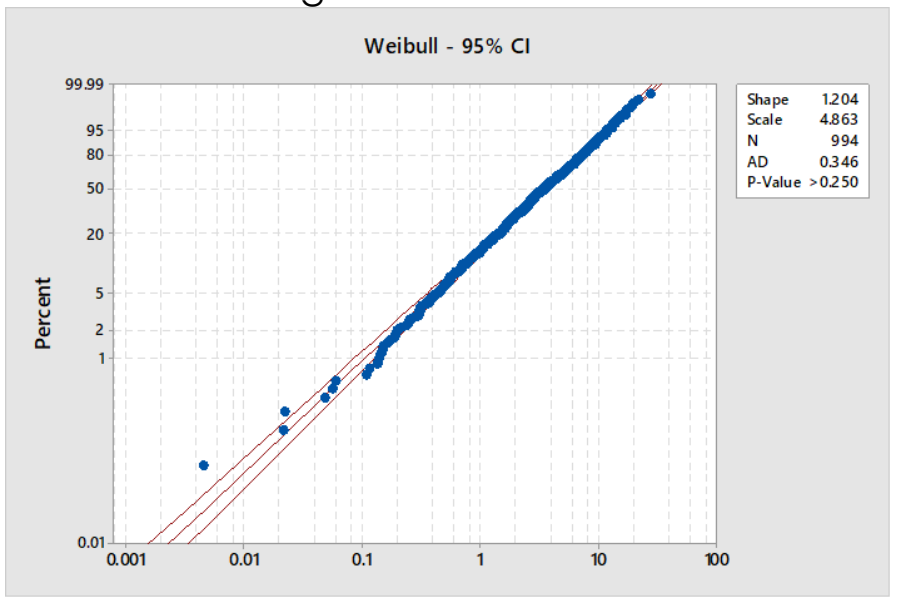

Source: Author's illustration

Figure 7

Anderson-Darling test for the spring (upper left), summer (upper right), autumn (lower left) and winter (lower right)

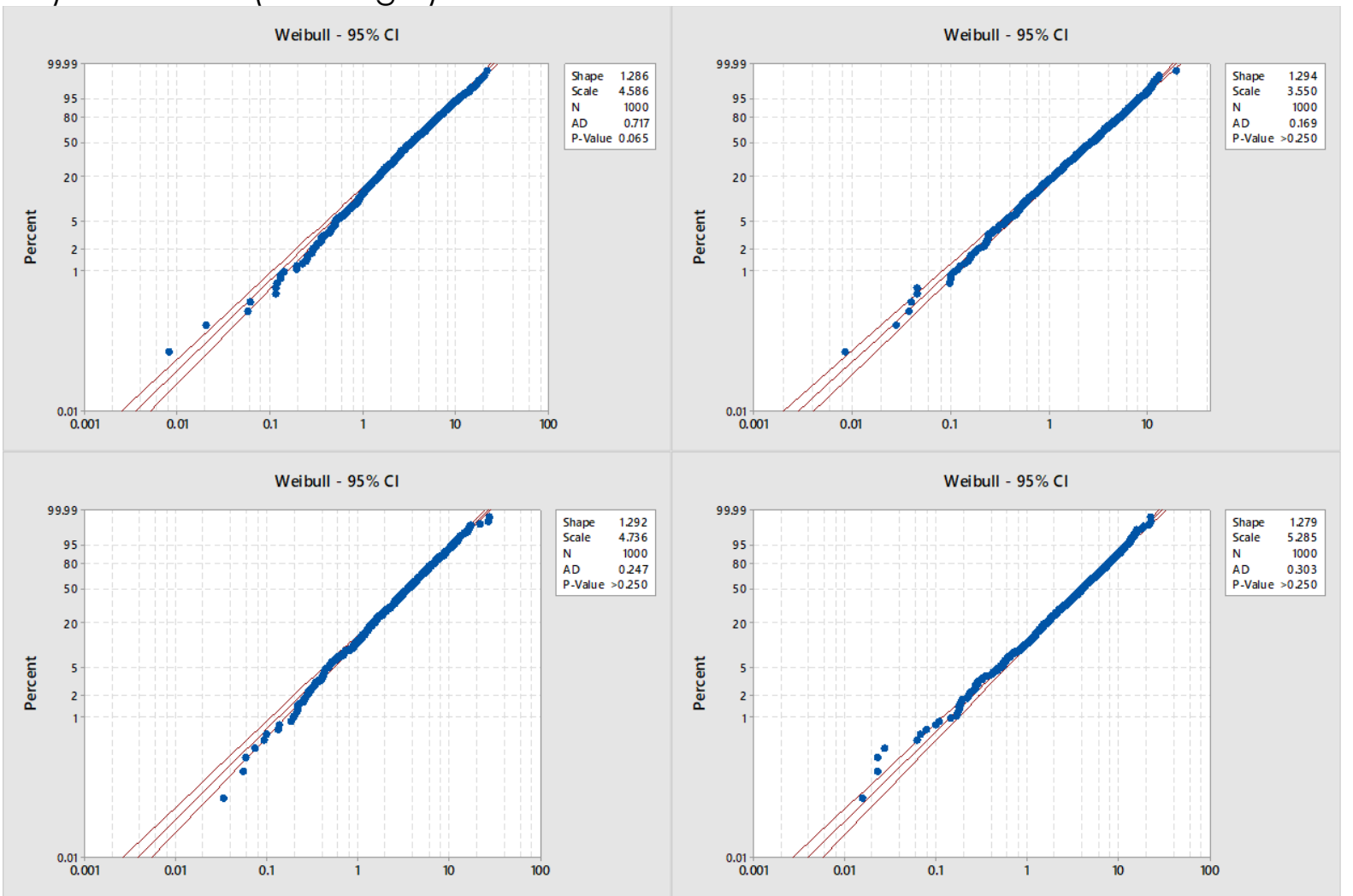

Source: Author's illustration 
By applying the Anderson-Darling test it is shown that the data follows the Weibull distribution for the annual level, Figure 6 , as well as for each season, figure 7. Because the $p$-value $(p>0.250)$ is higher than a reasonable choice of $\alpha(\alpha=0.05)$ there is no significant evidence to reject the null hypothesis stating that the data follows the Weibull distribution. The scale and shape parameters of the Weibull PDF are shown in Figures 6 and 7.

To visualize the Weibull PDF, the probability distribution plot is used. Plot of the Weibull PDF for the annual level is shown in Figure 8 and plots of the Weibull PDFs for each season are shown in Figure 9. Also, the probability of exceeding the medium wind speed of 5 degrees of the Beaufort wind scale $(v=9.35 \mathrm{~m} / \mathrm{s})$ is determined. This probability for the annual level is shown in Figure 8, while in Figure 9 the probability of exceeding is shown for each season.

Figure 8

The obtained Weibull PDF for the annual level

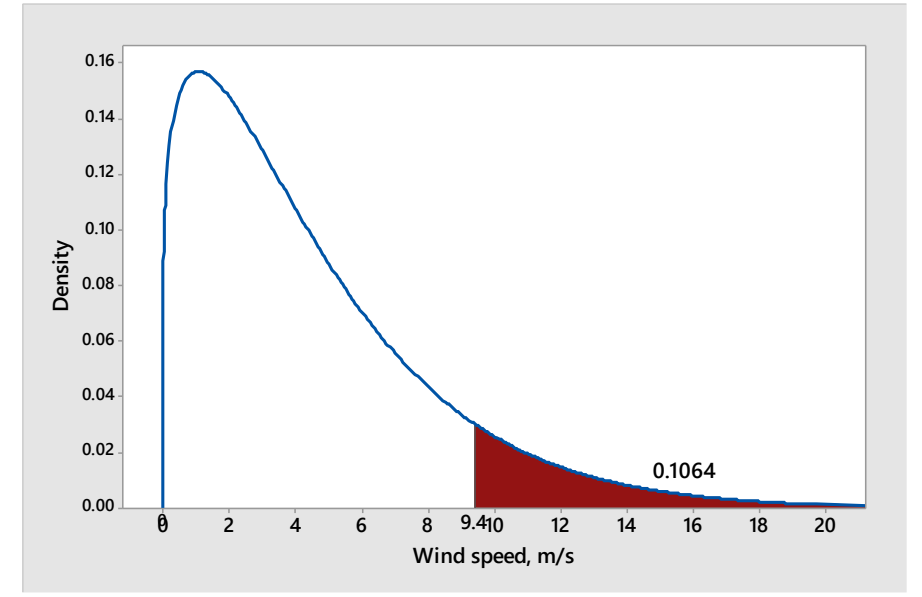

Source: Author's illustration

Based on the Weibull PDF for the annual level, with a shape parameter of 1.204 and a scale parameter of 4.863 , it can be concluded that in $10.64 \%$ of cases the wind speed will be equal to or higher than $9.35 \mathrm{~m} / \mathrm{s}$. Therefore, there is a probability of $10.64 \%$, that catamarans or ferries will not depart from the Split city port. From Figure 9, it can be seen that the probability of exceeding is significantly lower for the summer than for other seasons and it equals to $2.85 \%$. This was expected since in the summer average wind speeds are lower than in the other seasons. Furthermore, calm wind conditions during the summer in the Split area are the most frequent. For the spring, this probability is equal to $8.07 \%$, for the autumn is equal to $8.85 \%$, while for the winter the probability of exceeding is the highest and it equals to $12.54 \%$. 
Figure 9

The obtained Weibull PDF for the spring (upper left), summer (upper right), autumn (lower left) and winter (lower right)
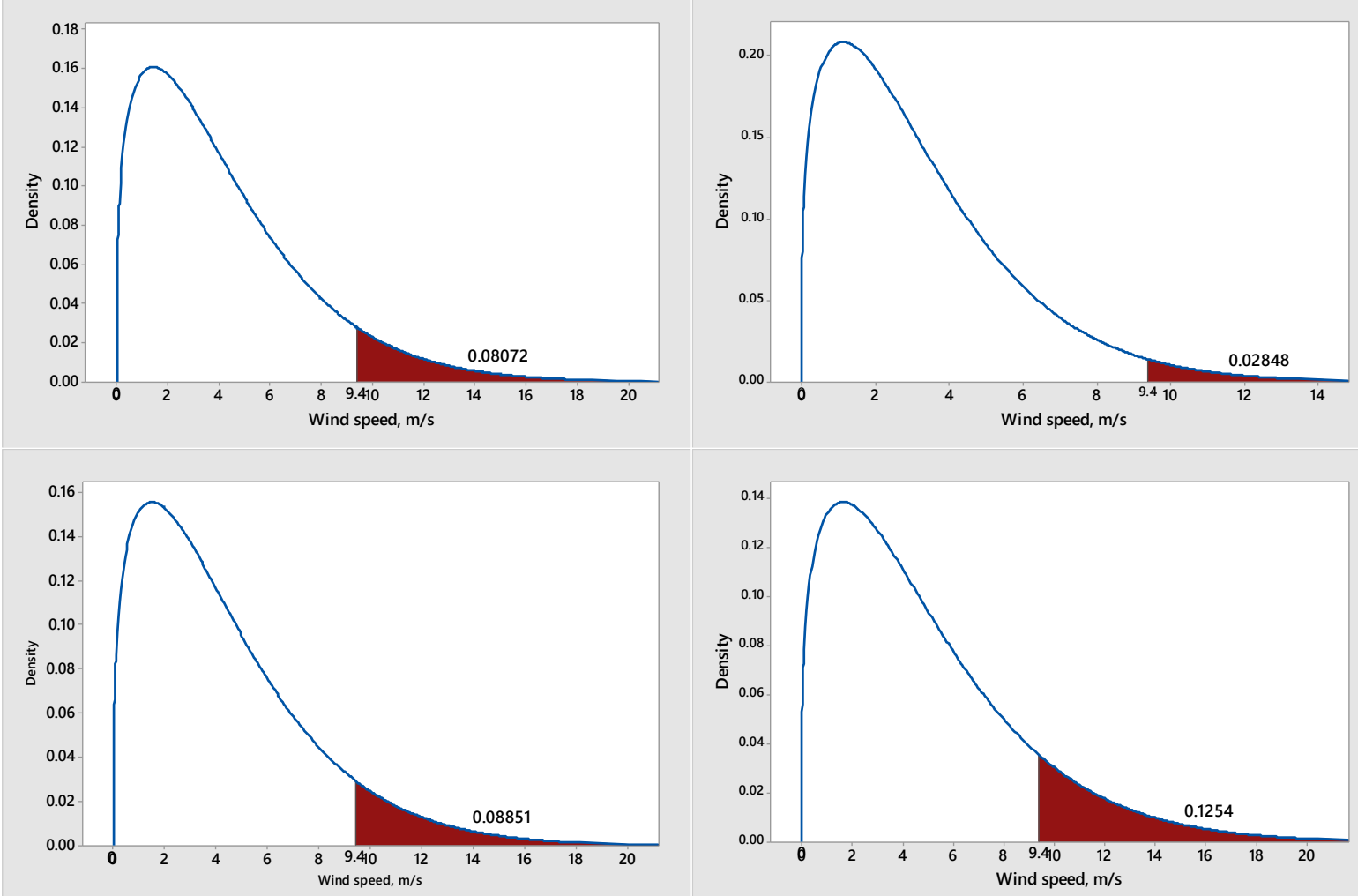

Source: Author's illustration

As catamaran and ferry departure represents a very important aspect for islanders, the obtained probabilities can be described as relatively high, but expected, since the split area represents a very windy area. Therefore, the probability of exceeding is also calculated for the medium wind speed of 6 degrees of the Beaufort wind scale for the annual level, Figure 10. The obtained probability of exceeding for the annual level is significantly lower than the one obtained for 5 degrees of the Beaufort wind scale and it equals to $4.54 \%$. Therefore, it can be concluded that ships with better seakeeping characteristics would assure better connection with the islands and improve the quality of lives of islanders.

Figure 10

The obtained probability of exceeding for the medium wind speed of 6 degrees of the Beaufort wind scale

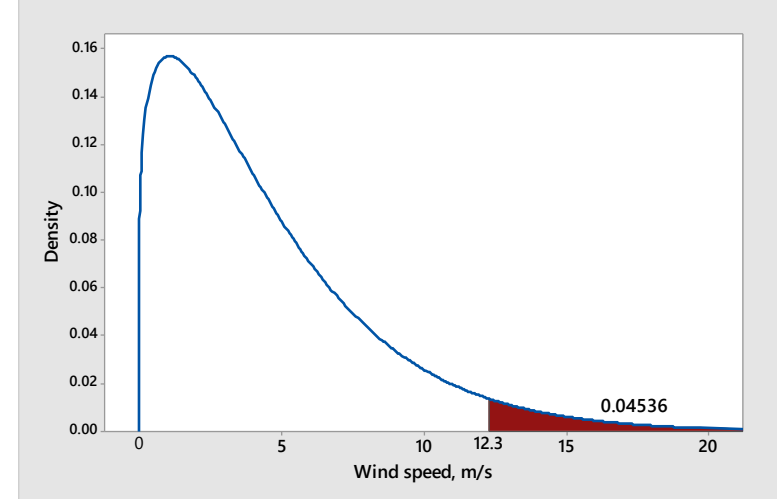

Source: Author's illustration 


\section{Conclusion}

Within this paper, the Weibull PDF is used for adjusting the wind speed data. The Anderson-Darling test was used to determine whether the data follows the Weibull distribution. Results showed that the Weibull PDF is suitable for the description of wind speed data. From the obtained Weibull PDF, the probabilities of exceeding are calculated for the annual level as well as for each season. The probability of exceeding is calculated for the medium wind speed of 5 degrees of the Beaufort wind scale. The aim of this research was to predict a probability of cancelled departure of catamarans and ferries. The obtained probabilities can be considered as relatively high and therefore the probability of exceeding for the medium wind speed of 6 degrees of the Beaufort wind scale is calculated as well. These probabilities are significantly lower and therefore it can be concluded that Croatian sea shipping company Jadrolinija could invest in ferries with better seakeeping characteristics in order to improve better connection with the islands and consequently improve the quality of lives of islanders.

In order to further investigate the wind regimes, wind roses were created. Wind roses were used for the visualization of frequency and average wind speed for particular wind direction.

The effect of wind on marine structures is not only conditioned by its speed but its duration as well. This means that a strong wind blast can cause less structural loads or can have less influence on the wave formation than a longer lasting wind having lower speed. Therefore, in future studies the wind duration will be included in the analysis of the effect of the wind on the cancelled departures of the catamarans and ferries. Furthermore, future studies will include additional analysis of strong and stormy winds in the required area in order to take into account these effects as well.

\section{References}

1. Carrillo, C., Cidrás, J., Díaz-Dorado, E., Obando-Montaño, A.F. (2014), „An approach to determine the Weibull parameters for wind energy analysis: the case of Galicia (Spain)", Energies, Vol. 7 No.4, pp. 2676-2700.

2. Christopher, J., Schindler, D., Laible, J., Buchholz, A. (2017), „Introducing a system of wind speed distributions for modeling properties of wind speed regimes around the world", Energy Conversion and Management, Vol. 144, pp. 181-192.

3. ECA (2015), ,Maritimna studija za ugradnju pontona za prihvat hidroaviona na dijelu Obale kneza Domagoja u gradskoj luci Split", European Coastal Airlines, Split.

4. Masseran, N., Razali, A.M., Ibrahim, K., Zaharim, A., Spian, K. (2013), "The probability distribution model of wind speed over East Malaysia", Res J Appl Sci, Eng Technol, Vol.6 No. 10, pp.1774-1779.

5. Meaden, G. Terence, Kochev, S., Kolendowicz, L., Kosa-Kiss, A., Marcinoniene, I., Sioutas, M., Tooming, H., Tyrrell, J. (2007), „Comparing the theoretical versions of the Beaufort scale, the T-Scale and the Fujita scale", Atmospheric research, Vol. 83 No. 2 , pp. 446-449.

6. Morgan, E. C., Lackner, M., Vogel, R. M., Baise, L.G. (2011), „Probability distribution for offshore wind speeds", Energy Convers Manage, Vol. 52, pp.15-26.

7. NIST/SEMATECH, (2013), "e-Handbook of Statistical Methods", available at: http://www.itl.nist.gov/div898/handbook/ (27 May 2017)

8. Omid, A., Kasra, M., Ali, M. (2016), „Evaluating the suitability of wind speed probability distribution models: a case of study of east and southeast parts of Iran", Energy Convers Manage, Vol. 119, pp. 101-8.

9. Pishgar-Komleh, S.H. and Akram, A. (2014), "Evaluation of wind energy potential for different turbine models based on the wind speed data of Zabol region, Iran", Sustainable Energy Technologies and Assessments, Vol. 22, pp. 34-40. 
10. Pishgar-Komleh, S.H., Keyhani, A., Sefeedpari, P. (2015), „Wind speed and power density analysis based on Weibull and Rayleigh distributions (a case study: Firouzkooh county of Iran)", Renew Sust Energy Rev, Vol. 42, pp. 313-22.

11. Pomorska enciklopedija (1989), "Beaufort, Francis", Vol 1, 2nd edition, Pomorska enciklopedija, Leksikografski zavod Miroslav Krleža, Zagreb, pp. 324-325.

12. Sarkar, A., Singh, S., Mitra, D. (2011), „Wind climate modeling using Weibull and extreme value distribution", Int J Eng Sci Technol, Vol. 3, pp.100-106.

13. Seguro, J. V., Lambert, T. W. (2000), "Modern estimation of the parameters of the Weibull wind speed distribution for wind energy analysis", Journal of Wind Engineering and Industrial Aerodynamics, Vol. 85 No. 1, pp. 75-84.

14. U.S. Congress, Office of Technology Assessment (1993), „The Future of Remote Sensing From Space: Civilian Satellite Systems and Applications", OTA-ISC-558, DC: U.S. Government Printing Office, Washington, pp. 33-44.

\section{About the authors}

Nastia Degiuli is a Full Professor at the Faculty of Mechanical Engineering and Naval Architecture, University of Zagreb, Department of Naval Architecture and Ocean Engineering. She received $\mathrm{PhD}$ in Marine Hydrodynamics at the Faculty of Mechanical Engineering and Naval Architecture, University of Zagreb with the dissertation thesis "Experimental Determination of Wave Pattern Resistance of the Wigley Trimaran Series". Her main research interests are experimental and computational fluid dynamics. She is actively engaged in number of science projects (FP7, national projects). Nastia Degiuli published numerous scientific papers in international and national journals and participated in many scientific international conferences. Author can be contacted at nastia.degiuli@fsb.hr.

Biserka Runje was educated (B.Sc. 1987, M.Sc. 1997, Ph.D. 2002) at the Faculty of Mechanical Engineering and Naval Architecture of the University of Zagreb. She is a Full Professor and Head of the Department of Quality at the same Faculty. Her professional interests include teaching and research in the field of Dimensional Metrology, Dimensional Nanometrology, Statistical Modeling in Metrology and Quality Management. She has authored and co-authored more than 50 published papers. Author can be contacted at biserka.runje@fsb.hr.

Andrea Farkas, mag. ing. nav. arch. is a research and teaching assistant at the Faculty of Mechanical Engineering and Naval Architecture, University of Zagreb, Department of Naval Architecture and Ocean Engineering. His main research interests are Computational Fluid Dynamics and Ship hydrodynamics. Andrea Farkas published two scientific papers in national journals and participated in several international and national conferences. Author can be contacted at andrea.farkas@fsb.hr. 